\title{
Laryngo-tracheal resections in the Nordic countries : an option for further centralization?
}

\section{Kiug, Tejs Ehlers}

2019-05

Kiug , T E , Hentze , M , Schytte , S, Farnebo , L , Rikardsen , O , Sihvo , E, Räsänen , J \& Mäkitie , A 2019 , ' Laryngo-tracheal resections in the Nordic countries : an option for further centralization? ' , European Archives of Oto-Rhino-Laryngology , vol. 276 , no. 5 , pp. 1545-1548 . https://doi.org/10.1007/s00405-019-05384-x

http://hdl.handle.net/10138/301527

https://doi.org/10.1007/s00405-019-05384-x

publishedVersion

Downloaded from Helda, University of Helsinki institutional repository.

This is an electronic reprint of the original article.

This reprint may differ from the original in pagination and typographic detail.

Please cite the original version. 


\title{
Laryngo-tracheal resections in the Nordic countries: an option for further centralization?
}

\author{
Tejs Ehlers Klug ${ }^{1}$ (D) Malene Hentze ${ }^{1}$ Sten Schytte ${ }^{1} \cdot$ Lovisa Farnebo $^{2,3} \cdot$ Oddveig Rikardsen $^{4} \cdot$ Eero Sihvo $^{5}$. \\ Jari Räsänen $^{6,7} \cdot$ Antti Mäkitie ${ }^{8,9,10}$
}

Received: 6 March 2019 / Accepted: 12 March 2019 / Published online: 19 March 2019

○) Springer-Verlag GmbH Germany, part of Springer Nature 2019

\begin{abstract}
Purpose We aimed to obtain information on the number of Nordic centers performing tracheal resections, crico-tracheal resections, and laryngo-tracheal reconstructions, as well as the patient volume and the standard regimens associated with these procedures.

Methods Consultants at all Departments of Otorhinolaryngology - Head and Neck Surgery (ORL-HNS, $n=22$ ) and Thoracic Surgery $(n=21)$ in the five Nordic countries were invited (April 2018-January 2019) to participate in an online survey.

Results All 43 departments responded to the survey. Twenty departments declared to perform one or more of the three types of tracheal resections. At five hospitals, departments of ORL-HNS and Thoracic Surgery perform these operations in collaboration. Hence, one or more of the tracheal operations in question are carried out at 15 centers. The median annual number of tracheal operations per center is five (range 1-20). Great variations were found regarding contraindications (relative and absolute) for surgery, the use of guardian sterno-mental sutures (all patients, 33\%; selected cases, $40 \%$ of centers), prophylactic antibiotic therapy (cefuroxime $+/-$ metronidazole, penicillin $+/-$ metronidazole, clindamycin, imipenem, or none), post-operative follow-up time (range: children: 3-120 months; adults: 0-60 months), and the performance of postoperative bronchoscopy.

Conclusions Fifteen centers each perform a low number of annual operations with significant variations in the selection of patients and the clinical setup, which raises the question if a higher degree of collaboration and centralization would be warranted. We encourage Nordic transnational collaboration, pursuing alignment on central management issues, and establishment of a common prospective database for future tracheal resection surgery.
\end{abstract}

Keywords Tracheal resection $\cdot$ Crico-tracheal resection $\cdot$ Management $\cdot$ Nordic countries

Tejs Ehlers Klug

tejsehlersklug@hotmail.com

1 Department of Otorhinolaryngology, Head and Neck Surgery, Aarhus University Hospital, Palle Juul-Jensens Boulevard 99, 8200 Aarhus N, Denmark

2 Department of Otolaryngology in Linköping, Anaesthetics, Operations and Specialty Surgery Center, Linköping, Region Östergötland, Sweden

3 Department of Clinical and Experimental Medicine, Division of Neuro and Inflammation Science, Linköping University, Linköping, Sweden

4 Department of Otorhinolaryngology, Head and Neck Surgery, University Hospital of North Norway, and University of Troms $\varnothing$-The Arctic University of Norway, Troms $\varnothing$, Norway
5 Department of Surgery, Central Finland Central Hospital, Jyvaskyla, Finland

6 Department of General Thoracic and Esophageal Surgery, Helsinki University Hospital, Helsinki, Finland

7 Department of Surgery, Clinicum, University of Helsinki, Helsinki, Finland

8 Department of Otorhinolaryngology, Head and Neck Surgery, University of Helsinki and Helsinki University Hospital, Helsinki, Finland

9 Research Programme in Systems Oncology, Faculty of Medicine, University of Helsinki, Helsinki, Finland

10 Division of Ear, Nose and Throat Diseases, Department of Clinical Sciences, Intervention and Technology, Karolinska Institutet and Karolinska Hospital, Stockholm, Sweden 


\section{Introduction}

Symptomatic stenoses of the subglottic larynx and trachea are relatively rare. The most common etiologies are prolonged intubation, previous tracheotomy, idiopathic lesions, tracheal trauma, and neoplastic lesions [1-5]. The majority of patients are adults with significant comorbidity $[1,2]$.

Endoscopic interventions (dilatation, electro or laser resection, and stenting) are widely used to provide relief of symptoms, but recurrences and need for reintervention(s) are frequent $[6,7]$. Single-stage (crico-)tracheal segmental resection with primary end-to-end anastomosis pose a radical alternative with reported long-lasting and high success rates [2]. However, the complex nature of the larynx and trachea makes these operations challenging and complications are common (9-56\%) even at specialized centers $[1,8,9]$. In a study of 1617 cases from 107 centers, Stanifer et al. found that low-volume centers $(<4$ operations annually) had significantly higher combined morbidity and mortality (27\%) compared with centers with more than four operations per year $(17 \%)(p<0.001)$ [1].

The Nordic countries have rather uniform taxationbased health care systems with every citizen having equal access to medical services. With a total population of approximately 26 million and long-lasting academic tradition, we were surprised to find that the number of publications on the volume, setup, selection of patients, and outcome of patients undergoing (crico-)tracheal segmental resection at Nordic centers was very limited [10-13]. We hypothesized that the reason for this lack of research reports was the performance of tracheal resections at a significant number of low-volume centers.

The current survey was carried out to obtain information on the number of Nordic centers performing (crico-) tracheal resections and laryngo-tracheal reconstructions, as well as patient volume, and standard regimens associated with these procedures.

\section{Materials and methods}

\section{Study design}

Consultants from all Departments of Otorhinolaryngology-Head and Neck Surgery (ORL-HNS) and Thoracic Surgery in the Nordic countries [Sweden (S), Finland $(\mathrm{F})$, Norway (N), Denmark (DK), and Iceland (I)] were invited via e-mail to participate in the online survey. Nonresponders were re-invited and additional personal calls for participation were done for sustained non-responders.

\section{Data collection}

Answers from the participating surgeons were collected using the Research Electronic Data Capture (REDCap) system. The study was conducted between April 21, 2018 and January 8, 2019.

\section{The questionnaire}

The following data were obtained from all participants: country, city, department (ORL-HNS/Thoracic Surgery), size of patient catchment area, national decision on centralization of crico-tracheal resections and/or laryngo-tracheal reconstructions, and which (of the mentioned) operations are carried out at the department. If one or more of these operations were performed, then more detailed information was obtained regarding indications for surgery, number of annual patients, relative and absolute contraindications for surgery, instructions for the use of sterno-mental sutures, length of intubation, length of intensive care and hospitalization, routine post-operative bronchoscopy, and use of antibiotics.

\section{Ethical considerations}

According to Danish law, approval from the research ethics committee for the study was not required.

\section{Results}

Survey responses were collected from all Departments of ORL-HNS $(n=22)$ and Thoracic Surgery $(n=21)$ in Norway $(n=3 / 4)$, Sweden $(n=9 / 6)$, Finland $(n=5 / 6)$, Denmark $(n=4 / 4)$, and Iceland $(n=1 / 1)$. In total, 20 departments declared to perform one or more of the three types of tracheal operations (tracheal resection, crico-tracheal resection, and laryngo-tracheal reconstruction). In five cities [Göteborg (S), Helsinki (F), Kuopio (F), Tampere (F), and Aarhus (DK)], departments of ORL-HNS and Thoracic Surgery performed operations in collaboration. In addition, the Department of ORL-HNS in Umeå (S) declared to collaborate with a center in Germany. Hence, one or more of the tracheal operations in question are carried out at 15 out of the 24 institutions in the Nordic countries (Table 1).

The median annual number of tracheal operations per center is five (range 1-20) (Table 2). Indications for surgery are non-neoplastic stenosis and tumor (benign and malignant) in the majority of centers (Table 3). Relative contraindications for surgery include low-performance status $(n=11)$, previous cervical radiation therapy $(n=6)$, high age ( $n=6$ ), impaired lung function $(n=4)$, high body mass index $(n=3)$, alcohol abuse $(n=2)$, smoking $(n=2)$, previous 
Table 1 Number of centers performing tracheal resections, crico-tracheal resections, and laryngo-tracheal reconstructions in children and adults in the Nordic countries

\begin{tabular}{|c|c|c|c|c|c|c|c|}
\hline \multirow[t]{2}{*}{ Country } & \multirow[t]{2}{*}{$\begin{array}{l}\text { Total no. of } \\
\text { centers }\end{array}$} & \multicolumn{2}{|c|}{ Tracheal resection } & \multicolumn{2}{|c|}{ Crico-tracheal resection } & \multicolumn{2}{|c|}{$\begin{array}{l}\text { Laryngo-tracheal } \\
\text { reconstruction }\end{array}$} \\
\hline & & Children & Adults & Children & Adults & Children & Adults \\
\hline Sweden & 5 & 2 & 4 & 2 & 2 & 1 & 2 \\
\hline Finland & 6 & 2 & 6 & 2 & 4 & 0 & 3 \\
\hline Norway & 3 & 0 & 3 & 0 & 2 & 0 & 1 \\
\hline Denmark & 1 & 0 & 1 & 0 & 1 & 0 & 0 \\
\hline Iceland & 0 & 0 & 0 & 0 & 0 & 0 & 0 \\
\hline Total & 15 & 4 & 14 & 4 & 9 & 1 & 6 \\
\hline
\end{tabular}

Table 2 Estimated median (range) number of annual tracheal resections, cricotracheal resections, and laryngo-tracheal reconstructions at the 15 centers in the Nordic countries

\begin{tabular}{|c|c|c|c|c|c|c|}
\hline \multirow[t]{2}{*}{ Country } & \multicolumn{2}{|c|}{ Tracheal resection } & \multicolumn{2}{|c|}{ Crico-tracheal resection } & \multicolumn{2}{|c|}{$\begin{array}{l}\text { Laryngo-tracheal recon- } \\
\text { struction }\end{array}$} \\
\hline & Children & Adults & Children & Adults & Children & Adults \\
\hline Sweden & $2(1-3)$ & $2(1-2)$ & $1.5(1-2)$ & $1(1-1)$ & $3(3-3)$ & $6.5(1-12)$ \\
\hline Finland & $1.5(1-2)$ & $1.5(1-5)$ & $1.5(1-2)$ & $1(1-3)$ & & $1(1-3)$ \\
\hline Norway & & $3(1-5)$ & & $2(2-2)$ & & $2(2-2)$ \\
\hline Denmark & & $5(5-5)$ & & $2(2-2)$ & & \\
\hline All & $2(1-3)$ & $2(1-5)$ & $1.5(1-2)$ & $1.5(1-3)$ & $3(3-3)$ & $1(1-12)$ \\
\hline
\end{tabular}

Table 3 Number of centres having a non-neoplastic stenosis or a tumor as an indication for tracheal surgery among the 15 Nordic centers

\begin{tabular}{llll}
\hline Country & \multicolumn{2}{l}{ Indications } & \\
\cline { 2 - 4 } & $\begin{array}{l}\text { Non-neoplastic } \\
\text { stenosis }\end{array}$ & Tumor & \\
\cline { 3 - 4 } & & Benign & Malignant \\
\hline Sweden & 5 & 4 & 4 \\
Finland & 4 & 5 & 6 \\
Norway & 2 & 1 & 3 \\
Denmark & 1 & 1 & 1 \\
Total & 12 & 11 & 14 \\
\hline
\end{tabular}

endoscopic treatment $(n=1)$, and individual assessment $(n=1)$. Absolute contraindications for surgery are previous cervical radiation therapy $(n=3)$, low-performance status $(n=3)$, impaired lung function $(n=3)$, high age $(n=3)$, alcohol abuse $(n=1)$, individual assessment $(n=1)$, and cardiovascular disease $(n=1)$.

Guardian sterno-mental sutures are instructed to be used for all patients at $5(33 \%)$ centers and in selected cases at 6 $(40 \%)$ centers for a median of 7 days (range 3-10). Patients are extubated on the day of surgery at $93 \%, 78 \%$, and $75 \%$ of centers performing tracheal resections, crico-tracheal resections, and laryngo-tracheal reconstructions, respectively. Patients are routinely observed post-operatively at an intensive care unit for a median of $14 \mathrm{~h}$ (range 0-24) with minimal differences between the three types of operations. The median standard duration of hospitalization is 7 days (range 1-14) with minimal differences between types of operations. Patients undergoing tracheal resections, cricotracheal resections, and laryngo-tracheal reconstructions are routinely given prophylactic antibiotic therapy at $87 \%, 89 \%$, and $100 \%$ of the centers, respectively. The antibiotics used are cefuroxime with $(n=5)$ or without $(n=5)$ additional metronidazole, penicillin $\mathrm{G}$ with $(n=1)$ or without metronidazole $(n=1)$, clindamycin $(n=1)$, and imipenem $(n=1)$ for a median of 4 days (range 1-7).

The median post-operative follow-up time is 24 months (range 3-120) in children and 12 months (range 0-60) in adults. Post-operative bronchoscopy is performed routinely in $71 \%, 90 \%$, and $86 \%$ of the centers after tracheal resections, crico-tracheal resections, and laryngo-tracheal reconstructions, respectively. At the remaining centers, post-operative bronchoscopy is carried out in selected cases only. The median time period between surgery and follow-up bronchoscopy is 6 weeks (range 1-12).

\section{Discussion}

The aim of the current study was to describe the current status of tracheal resection surgery in the five Nordic countries. Discussing specific regimen issues and providing a management protocol were left out from the present work. Receiving information from all Departments of ORL-HNS and Thoracic Surgery in this area, we found that 15 centers each perform a low number of annual operations with significant variations in the selection of patients and the clinical 
set up. In fact, 6 (40\%) out of these 15 centers claimed to perform only one or two operations (all three types combined) per year.

Segmental (crico-)tracheal and laryngo-tracheal reconstruction constitutes a demanding area with highly specialized operations with significant complication rates $[1-3,13$, 14]. Complications include recurrent nerve palsy (unilateral or bilateral), mediastinitis, pneumonia, dysphagia, haemorrhage, tracheo-oesophageal fistula, and death (0-3\%) [1-3]. A number of risk factors (e.g., large resections, pediatric surgery, co-morbidity, previous tracheotomy, or other treatment) for poor outcome and complications have been found, and careful preoperative patient selection is crucial to achieve high success rates and acceptable complication rates $[1,2,8,13]$. We found great differences in the relative and absolute contraindications for surgery between the 15 Nordic centers. Significant variations regarding the use of sterno-mental sutures, the preferred antibiotic regimen, and post-operative observation, hospitalization, and follow-up were also found. Some of the regime heterogeneity may be explained by differences in geography and local bacterial resistance patterns, while others are likely to reflect the lack of consensus on multiple issues regarding the optimal setup for tracheal resection surgery.

In conclusion, due to the limited number of published studies on the outcome of these operations, we do not find it feasible to analyze and compare the outcome of tracheal resections in the Nordic countries in a collective manner and in relation to large-volume centers elsewhere. However, our findings raise the question if a higher degree of collaboration and centralization, within and across these countries, is appropriate. The issue of centralization seems especially evident in the management of adults with these lesions in Finland, Norway, and Sweden and in children throughout Scandinavia. The authors encourage such Nordic national and transnational collaboration. Pursuing alignment on central management issues and establishing a common prospective database for future (crico-)tracheal resection surgery seem to be feasible.

\section{Compliance with ethical standards}

Conflict of interest The author(s) declare that they have no competing interests.

Ethical approval According to Danish law, no ethical approval is necessary in questionnaire studies.

Informed consent Informed consent was obtained from all individual participants included in the study.

\section{References}

1. Stanifer BP, Andrei AC, Liu M, Meyerson SL, Bharat A, Odell DD, DeCamp MM (2018) Short-term outcomes of tracheal resection in the society of thoracic surgeons database. Ann Thorac Surg 106:1612-1618

2. Wright CD, Grillo HC, Wain JC, Wong DR, Donahue DM, Gaissert HA, Mathisen DJ (2004) Anastomotic complications after tracheal resection: prognostic factors and management. J Thorac Cardiovasc Surg 128:731-739

3. Mutrie CJ, Eldaif SM, Rutledge CW, Force SD, Grist WJ, Mansour KA, Miller DL (2011) Cervical tracheal resection: new lessons learned. Ann Thorac Surg 91:1101-1106

4. Marulli G, Rizzardi G, Bortolotti L, Loy M, Breda C, Hamad AM, Sartori F, Rea F (2008) Single-staged laryngotracheal resection and reconstruction for benign strictures in adults. Interact Cardiovasc Thorac Surg 7:227-30

5. Herrington HC, Weber SM, Andersen PE (2006) Modern management of laryngotracheal stenosis. Laryngoscope 116:1553-1557

6. Freitag L, Darwiche K (2014) Endoscopic treatment of tracheal stenosis. Thorac Surg Clin 24:27-40

7. Nouraei SA, Ghufoor K, Patel A, Ferguson T, Howard DJ, Sandhu GS (2007) Outcome of endoscopic treatment of adult postintubation tracheal stenosis. Laryngoscope 117:1073-1079

8. Piazza C, Del Bon F, Paderno A, Grazioli P, Mangili S, Lombardi D, Nicolai P, Peretti G (2014) Complications after tracheal and cricotracheal resection and anastomosis for inflammatory and neoplastic stenoses. Ann Otol Rhinol Laryngol 123:798-804

9. Bibas BJ, Terra RM, Oliveira Junior AL, Tamagno MF, Minamoto H, Cardoso PF, Pêgo-Fernandes PM (2014) Predictors for postoperative complications after tracheal resection. Ann Thorac Surg 98:277-282

10. Spandow O, Lindholm CE (1994) Granular cell tumour in a child's trachea-a diagnostic and therapeutic challenge. Int J Pediatr Otorhinolaryngol 30:159-166

11. Aaltonen PL, Puntila JT, Suominen PK, Mattila IP, Sairanen HI, Lindahl H, Salminen JT (2014) Resection of the stenotic segment with individually tailored anastomosis for symptomatic congenital tracheal stenosis in infants. Eur J Cardiothorac Surg 45:e215-e219

12. Nielsen VE, Pedersen U, Pilegaard H (2010) Surgical treatment of tracheal stenosis. Ugeskr Laeger 172:1289-1293

13. Hentze M, Schytte S, Pilegaard H, Klug TE (2019) Single-stage tracheal and cricotracheal segmental resection with end-to-end anastomosis: outcome, complications, and risk factors. Auris Nasus Larynx 46:122-128

14. Grillo HC, Donahue DM, Mathisen DJ, Wain JC, Wright CD (1995) Postintubation tracheal stenosis. Treatment and results. J Thorac Cardiovasc Surg 109:486-492

Publisher's Note Springer Nature remains neutral with regard to jurisdictional claims in published maps and institutional affiliations. 